\title{
Biodegradation of Turquoise Blue Dye by Bacillus Megaterium Isolated from Industrial Effluent
}

\author{
${\text { Bhoomi Joshi }{ }^{1} \text {, Khyati Kabariya }}^{2}$, Sweta Nakrani ${ }^{2}$, Arif Khan ${ }^{1}$, Farzin M. Parabia ${ }^{1}$, Hiren V. Doshi ${ }^{3}$, Mukund \\ Chandra Thakur ${ }^{1}{ }^{*}$ \\ ${ }^{1}$ Department of Biotechnology, Ashok \& Rita Patel Institute of Integrated Study and Research in Biotechnology and Allied Sciences \\ (ARIBAS), New Vallabh Vidyanagar, Gujarat, India \\ ${ }^{2}$ Department of Biotechnology, Government Science College, K. K. Shastri Educational Campus, Ahmedabad, Gujarat, India \\ ${ }^{3}$ Department of Pharmaceutical Chemistry, Ashok \& Rita Patel Institute of Integrated Study and Research in Biotechnology and Allied \\ Sciences (ARIBAS), New Vallabh Vidyanagar, Gujarat, India \\ *Corresponding author: mukundthakur@aribas.edu.in
}

Received December 31, 2012; Revised April 26, 2013; Accepted April 28, 2013

\begin{abstract}
Turquoise blue dye (Remazol Blue BB) is a reactive dye which is used by almost all textile industries. The sample was collected from dye industries near VATVA G.I.D.C. (Gujarat) and adjourning surrounding area. On the basis of colony morphology and certain biochemical tests the strain was identified as Bacillus megaterium species and gave maximum decolourization of turquoise blue dye within 48 hours at $\mathrm{pH} 7.00$ and $37^{\circ} \mathrm{C}$ in the medium followed by blue M2R, Safranin, Congo red, Malachite green Orange ME2RL and Yellow M8G dyes. This organism can decolourize turquoise blue dye up to a concentration of $5 \mathrm{mg} / \mathrm{ml}$ but showed maximum dye degradation at $1 \mathrm{mg} / \mathrm{ml}$ concentration. Glucose $(1 \mathrm{~g} \%)$ was found to be the best Carbon source while $\mathrm{NH}_{4} \mathrm{Cl}(1 \mathrm{~g} \%)$ was found as the best Nitrogen source for maximum biodegradation process. The isolated strain is even able to degrade wide range of dyes. Further, there is a need to test this organism at large scale degradation of this dye.
\end{abstract}

Keywords: Biodegradation, turquoise blue dye, Bacillus megaterium

\section{Introduction}

Dyes are widely used in the textile, rubber, paper, printing, colour photography, pharmaceuticals, cosmetics and many other industries [1]. It has been estimated that about 10,000 different types of dyes are being industrially used worldwide. The synthesis of dyes is a complex process. They are normally manufactured from the primary products obtained through the distillation of coaltar [2]. During the dyeing processes about $10-90 \%$ of the dye do not bind to the fibers and therefore are released into the environment $[3,4]$.

Reactive dyes have been increasingly used in industries because of their cost effectiveness in synthesis as compared to natural dyes. Colour is the first contaminant to be recognized in the wastewater and has to be removed before discharging into water bodies or on land. The removal of colour from wastewater is often more important than the removal of soluble colourless organic substances, which usually contribute the major fraction of biochemical oxygen demand (BOD) [5]. These dyes resist biodegradation, and several of them and/or their products are toxic [6]. Moreover because the presence of complex aromatic molecular structures of these dyes on the exposure to sweat, soap, water, light or oxidizing agents gets restricted $[7,8]$. Among these dyes, turquoise blue QG, a well known reactive dye, is widely used in the textile industry. The resulting textile wastewater is of a deep blue colour that affects water quality by inhibiting the penetration of sunlight and thus reducing photosynthetic activity $[9,10]$. Reactive dyes have large and important group of chemical pollutants for aquatic ecosystem because of their toxicity and carcinogenicity [5,11]. Disposal of these dyes into the environment causes serious damage, since they may significantly affect the photosynthetic activity of hydrophytes by reducing light penetration [12]. The presence of very small amounts of dyes in water $(<1 \mathrm{ppm})$ is highly visible and affects the aesthetic merit, water transparency and gas solubility in lakes, rivers and other water bodies [5]. Moreover, numerous reports indicate that textile dyes and effluents have toxic effects on the germination rates and biomass of several plant species which have important ecological functions, such as providing a habitat for wildlife, protecting soil from erosion and providing the organic matter that is so significant to soil fertility [13].

Environmental regulatory agencies in several countries are adopting stringent regulations for the discharge of coloured effluents from textile and dyestuff manufacturers. The cities of Kingston and Toronto (Ontario, Canada) modified their municipal by-laws in 2000 to prohibit the discharge of coloured effluents to the municipal sewage $[14,15]$. 
There are a number of physical $[16,17]$ and chemical treatments [18,19] for colour removal from textile wastewater. Activated carbon adsorption processes are often used for this purpose due to their versatility, efficiency and low operating costs [10]. Owing to its structural characteristics, specifically its large surface area and high pore distribution, activated carbon is a highly efficient adsorbent.

Compared with chemical/Physical methods, biological processes have received more interest because of their cost effectiveness, lower sludge production and environmental friendliness [20]. Under static or anaerobic conditions, bacterial decolourization generally demonstrates good colour removal effects [20]. A number of environmental factors including both dye and non-dye related parameters are reported in literature, which directly or indirectly influences the process. These factors include temperature, dissolved oxygen, redox mediators, type of microorganisms, amount of nutrients, type and chemical structure of dye under study $[21,22,23]$. The present work included the use of Bacillus megaterium population, which are intrinsic part of these effluent channels and can tolerate the antagonistic conditions. Moreover it included decolourization of two commonly used reactive dye i.e. Direct Blue 86.

\section{Materials and Methods:}

\subsection{Collection of Samples}

The bacterial isolate was obtained from the water of sari printing effluent \& soil polluted with dyes. The sample was collected from dye industries near VATVA G.I.D.C. (Gujarat) and adjourning surrounding area. The different dye soil sample was collected in sterilized polypropylene bags and brought to the laboratory.

\subsection{Isolation of Dye Degrading Organisms}

The collected wastewater and soil sample was inoculated in sterilized nutrient agar medium containing different dyes as per the method described by Thakur et al [24]. Serial dilutions up to 10-3 was made from wastewater $(10 \mathrm{ml}$ in $90 \mathrm{ml})$ and soil sample $(10 \mathrm{~g}$ in $100 \mathrm{ml})$ separately. The nutrient agar medium was inoculated with $100 \mu \mathrm{l}$ of suspensions separately and incubated at $37^{\circ} \mathrm{C}$ for up to 100 hours. After incubation the observations for the zone of clearance/decolourization on the respective plates were recorded. The single pure culture showing zone of decolourization was characterised on the basis of morphology of culture and biochemical tests according to the IXth edition, Bergey's manual of determinative Bacteriology (2000).

\subsection{Selection of Dye}

There were seven different dyes (blue M2R, Orange ME2RL, Yellow M8G, Turquoise blue QG, Safranin, Congo red and Malachite green) used in the present study. All the dyes had $0.1 \mathrm{mg} / 10 \mathrm{ml}$ concentration in each tubes separately. The pure culture of organism was inoculated to each of the tubes and incubated at different temperatures $\left(25^{\circ} \mathrm{C}, 30^{\circ} \mathrm{C}, 37^{\circ} \mathrm{C}, 45^{\circ} \mathrm{C}\right.$ and $\left.55^{\circ} \mathrm{C}\right)$. The efficiency for the degradation of dyes by isolate was noticed. Control for each dye was also prepared separately in which inoculums was added in sterilized medium. The culture of the tubes was harvested after 24 and 48 hours consecutively and content of the tubes were centrifuged at $7000 \mathrm{rpm}$ for 15 min and supernatant was analyzed spectrophotometrically for any residual dye at 254nm [25].

\subsection{Primary Screening of Dye Decolourizing Microorganisms}

A set of 15 test tubes containing Glucose Peptone Yeast Extract (GPY) medium were taken. In all tubes $1 \mathrm{ml}$ of $1 \mathrm{mM}$ concentration of turquoise blue dye was added. The $\mathrm{pH}$ was maintained at 7.0 and autoclaved at $121^{\circ} \mathrm{C}$ for 15 min. All the test tubes were divided in three sets equally (5 test tubes in each set). About $10 \mathrm{ml}, 1 \mathrm{ml}$ and $0.1 \mathrm{ml}$ soil sample was added to 1 st set, second set and 3rd set respectively and incubated at $37^{\circ} \mathrm{C}$ for one week.

\subsection{Secondary Screening of Dye Decolourizing Microorganisms}

The GPY plate containing $1 \mathrm{mM}$ Turquoise blue was prepared. The liquid culture from the growth medium (GPY tube showing maximum decolourization) was spread on GPY plates and incubated at $37^{\circ} \mathrm{C}$ for 24 hrs. After incubation, the plate was observed for zone of decolourization.

\subsection{Optimization of the Dye Concentration}

A set of test tubes containing sterilized $10 \mathrm{ml}$ G.P.Y. medium with different concentration of dyes $(1 \mathrm{mg} / \mathrm{ml}$ to $5 \mathrm{mg} / \mathrm{ml}$ ) was inoculated with $18 \mathrm{hrs}$ old culture and incubated at $37^{\circ} \mathrm{C}$. A set of tubes was harvested after 24 and 48 hours consecutively and content of the tubes were centrifuged at $7000 \mathrm{rpm}$ for $15 \mathrm{~min}$ and supernatant was analyzed spectrophotometrically for any residual dye at 254nm [25].

\subsection{Optimization of Carbon and Nitrogen Source in the Medium}

In this experiment different carbon and nitrogen sources were used keeping the dye concentration same.

\subsubsection{Optimization of Different Carbon Source Concentration for Dye Degradation}

A set of tubes containing different sugars (glucose, sucrose, mannitol, maltose, lactose and cellulose) were prepared. Control tubes were also prepared together with the experimental one. In control inoculums was not added and dye concentration was same in all tubes. A set of test tubes containing $10 \mathrm{ml}$ of medium and $0.1 \mathrm{mg}$ dye were sterilized at $121^{\circ} \mathrm{C}$ for $15 \mathrm{~min}$. The tubes were inoculated with 18 hours old culture separately and incubated at $37^{\circ} \mathrm{C}$. The tubes were centrifuged at $7000 \mathrm{rpm}, 15 \mathrm{~min}$ and supernatant was analyzed spectrophotometrically for residual dye at $254 \mathrm{~nm}$ as per the method described by Chen et al [25]. The results for the decolourization of medium were observed for each tube containing different sugars. 


\subsubsection{Optimization of Organic and Inorganic Nitrogen Concentration for Dye Degradation}

A set of tubes containing different nitrogen sources ( $\mathrm{NH}_{4} \mathrm{Cl}, \mathrm{NH}_{4} \mathrm{OH}, \mathrm{NaNO}_{3}$, urea, peptone) were prepared. Control tubes were also prepared together with the experimental one. In control inoculums was not added and dye concentration kept same in all tubes. A set of test tubes containing $10 \mathrm{ml}$ of medium with $0.1 \mathrm{mg}$ dye were sterilized at $121^{\circ} \mathrm{C}$ for $15 \mathrm{~min}$. The tubes were inoculated with 18 hours old culture and incubated at $37^{\circ} \mathrm{C}$. The culture medium in each tube was centrifuged at 7000rpm for $15 \mathrm{~min}$ and supernatant was analyzed spectrophotometrically for residual dye at $254 \mathrm{~nm}$ [25].

\subsection{Effect of Temperature on Dye Degradation}

A set of test tubes containing sterilized $10 \mathrm{ml}$ G.P.Y. medium with $0.1 \mathrm{mg}$ dye was inoculated with $18 \mathrm{hrs}$ old culture and incubated at different temperatures $\left(25^{\circ} \mathrm{C}\right.$, $30^{\circ} \mathrm{C}, 37^{\circ} \mathrm{C}, 45^{\circ} \mathrm{C} \& 55^{\circ} \mathrm{C}$ ). The culture of the tubes was harvested after 24 and 48 hours consecutively and content of the tubes were centrifuged at $7000 \mathrm{rpm}$ for $15 \mathrm{~min}$ and supernatant was analyzed spectrophotometrically for any residual dye at 254nm [25].

\subsection{Effect of pH on Dye Degradation}

A set of test tubes containing sterilized $10 \mathrm{ml}$ G.P.Y. medium, $0.1 \mathrm{mg}$ dye prepared at different $\mathrm{pH}(5,6,7,8,9$, 10) was inoculated with 18 hrs old culture and incubated at $37^{\circ} \mathrm{C}$. The culture of the tubes was harvested after 24 and 48 hours consecutively and content of the tubes were centrifuged at 7000rpm for $15 \mathrm{~min}$ and supernatant was analyzed spectrophotometrically for any residual dye at 254nm [25].

\section{Results and Discussion}

\subsection{Identification of the Dye Degrading Strain}

The colony morphology of the isolate was irregular, entire convex, soft and creamy white in colour. Gram staining experiment was performed and the results showed that the isolate was gram positive and long rod bacteria. On the basis of colony morphology and certain biochemical tests (Table 1) the strain was identified as Bacillus megaterium species.

Table 1. Detailed identification of isolate

\begin{tabular}{|c|c|}
\hline BIOCHEMICAL TESTS & RESULTS \\
\hline Motility & -ve \\
\hline Iodole production & -ve \\
\hline Methyl red test & +ve \\
\hline Vogous prausker test & +ve \\
\hline Citrate utilization test & -ve \\
\hline $\mathrm{H}_{2}$ S production test & -ve \\
\hline Gelatin utilization test & $+\mathrm{ve}$ \\
\hline Catalase production test & $+\mathrm{ve}$ \\
\hline Urea hydrolysis & -ve \\
\hline Starch hydrolysis & +ve \\
\hline Sugar fermentation & \\
\hline Arbinose & +ve \\
\hline
\end{tabular}

\begin{tabular}{|c|c|}
\hline Xylose & +ve \\
\hline Maltose & $+\mathrm{ve}$ \\
\hline Sucrose & $+\mathrm{ve}$ \\
\hline Manitol & $+\mathrm{ve}$ \\
\hline Glucose & -ve \\
\hline Lactose & -ve \\
\hline
\end{tabular}

+ve indicates positive and -ve indicates negative

On the basis of the morphological as well as biochemical characteristics the isolate was identified as Bacillus megaterium. Thus the results of several experiments conducted on $B$. megaterium.

\subsection{Optimization of Dye Degradation by $B$. megaterium}

Out of seven dyes used, turquoise blue QG dye showed maximum decolourisation in the medium followed by blue M2R, Safranin, Congo red, Malachite green, Orange ME2RL and Yellow M8G dyes (Figure 1).

Turquoise blue dye (Direct dye): Remazol Blue BB is a reactive dye. All fiber reactive dyes are anionic, since they have negative molecular charges. The reactive group for Remazol Blue BB, as indicated by its name, places it in the vinyl sulfone class, where the chromophore places it in the group of copper formazans [26].

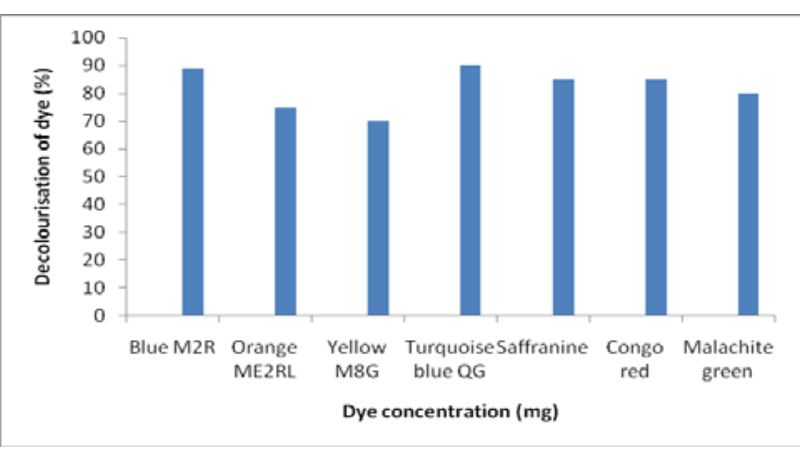

Figure 1. Representing \% Dye decolourization in 48 hrs of different dyes

\subsection{Primary and Secondary Screening of Dye Decolourizing Organism}

It can be seen from the primary studies (Figure 2a \& b) that the isolate showed maximum decolourization for turquoise blue dye and therefore was selected for further study. The dye degrading isolate gave decolourization Zone on Petri dish (Figure 3). This isolate had good ability to degrade the turquoise blue dye (up to $95 \%$ ) in $10 \mathrm{mM} /$ $10 \mathrm{ml}$ medium concentration within 48 hours.

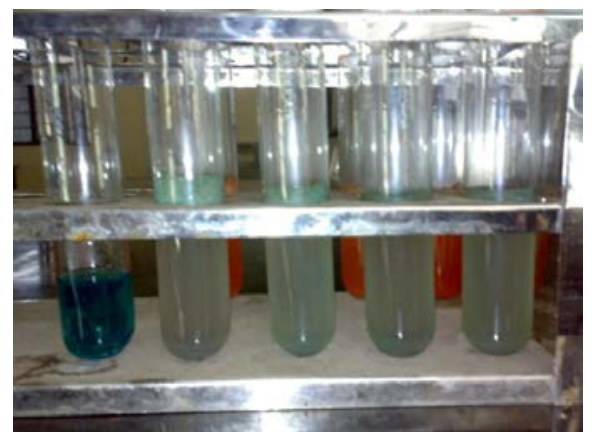

Figure 2a. Showing dye degradation 


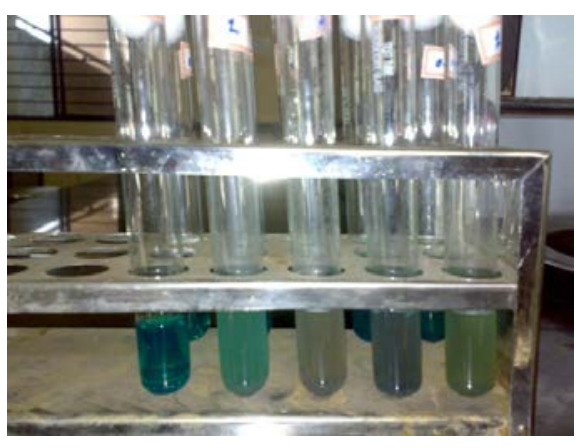

Figure 2b. Set-2 (tubes 6 to 10 )

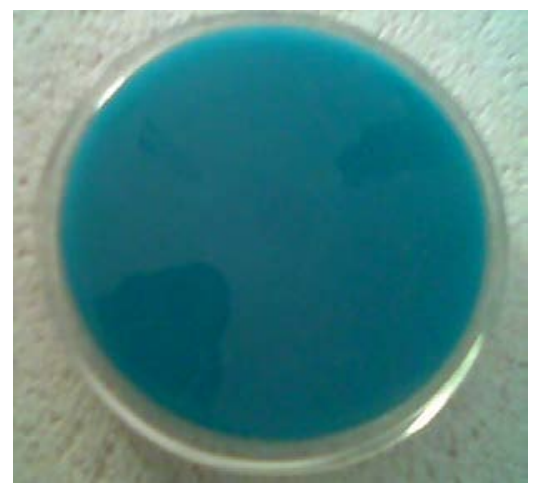

Figure 3a. Control plate

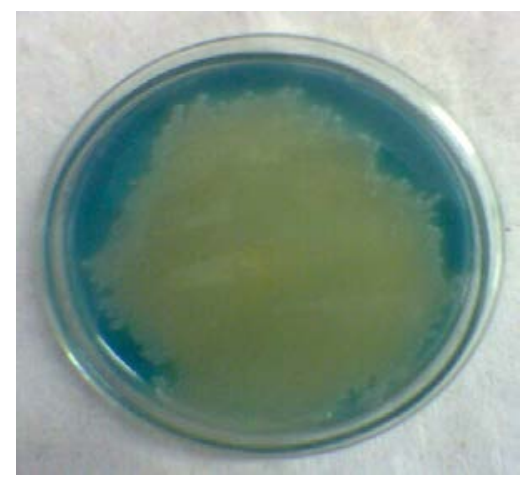

Figure 3b. Plate showing dye degradation

The degradation of dye substrates and decolourizing efficiency was dependent on the growth of the isolate in the flask. There was neither growth nor decolourization in the control flasks. This showed that the decolourization was due to the metabolic activity of the organisms and not due to any abiotic factors. The effluent samples colour was varied greatly depending upon their collection point that may be due to the variation of dye residual concentrations in the samples.

\subsection{Optimization of the Dye Concentration}

The B. megaterium showed maximum dye degradation at $1 \mathrm{mg} / \mathrm{ml}$ concentration (Figure 4 ). The decrease in the decolourisation efficiency was seen to be decreased with increase in the concentration of the dyes. Least dye degradation was observed in $5 \mathrm{mg} / \mathrm{ml}$ concentration.

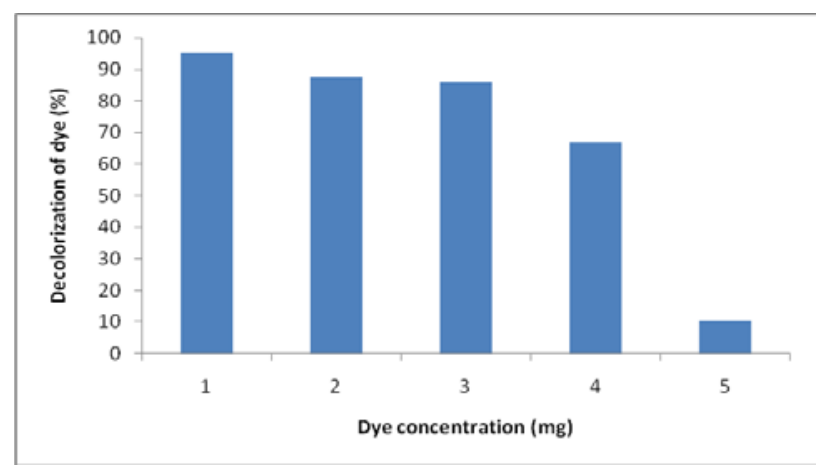

Figure 4. Degradation of dye in different concentration

The maximum decolourization was observed at dye concentration, the increase in dye concentration reduces the decolourization rate. Similar observations have been recorded earlier for decolourization of triphenylmethane dyes by Kurthia sp [27,28].

\subsection{Optimization of Carbon and Nitrogen Source in the Medium}

Attempts were made to alter the composition of the medium by altering the carbon source, nitrogen source and the results thus obtained is given in Figure 5 and Figure 6. The glucose and sucrose were found to be best suitable carbon source for the growth of $B$. megaterium.

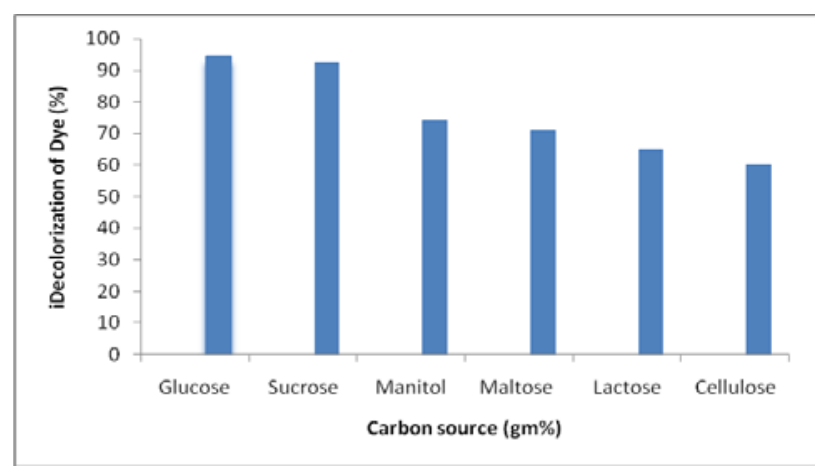

Figure 5. Optimisation of carbon source

$\mathrm{NH}_{4} \mathrm{Cl}$ was found suitable as nitrogen source while the peptone supported the least among the five different types of nitrogen sources used in the present study.

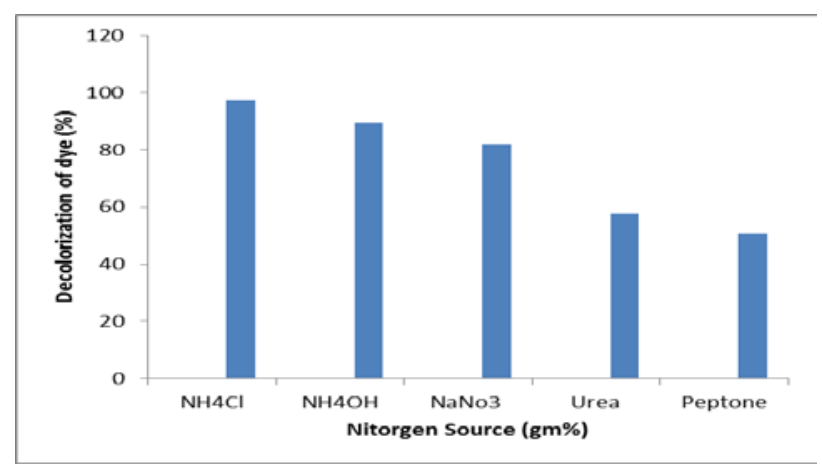

Figure 6. Optimisation of nitrogen source

Bacterial utilization of azo dyes as a source of carbon, energy [29,30] and nitrogen source [31,32] have been reported by several worker. This study is perhaps one of 
the few reports in the literature on the utilization of reactive dye turquoise blue as a source of carbon and nitrogen. Glucose and yeast extract were employed as cosubstrates, as a requirement for a metabolizable carbon source seems to be obligatory for functioning of dyedecolourizing bacteria.

The moderately halotolerant Bacillus sp. isolated in this study decolourized the reactive dye turquoise blue to a extent of $84 \%$.This rate of decolourization may be due to the high metabolic diversity being seen in the halophiles due to their extremophilic nature[33,34]. Decolourization of synthetic dyes is due to the cleavage of the chromophoric group which generates colourless metabolic intermediates. These intermediate metabolites of the dye substrates are aromatic amines [35]. The results obtained in Table proved, maximum decolourization occurs in Glucose (1gm\%), $\mathrm{NH}_{4} \mathrm{Cl}$ (1gm \%) in $24 \mathrm{hrs,} \mathrm{in} \mathrm{compare} \mathrm{to}$ optimal condition for $\mathrm{B}$. cereus was found to be $1 \%$ sucrose $0.25 \%$ peptone [36].

\subsection{Effect of Temperature on Dye Degradation}

The bacteria could grow well at $37^{\circ} \mathrm{C}$ followed by $45^{\circ} \mathrm{C}$, $55^{\circ} \mathrm{C}$ and $10^{\circ} \mathrm{C}$ (Figure 7). Thus the optimum temperature for the growth and dye degradation for $B$. megaterium was $37^{\circ} \mathrm{C}$.

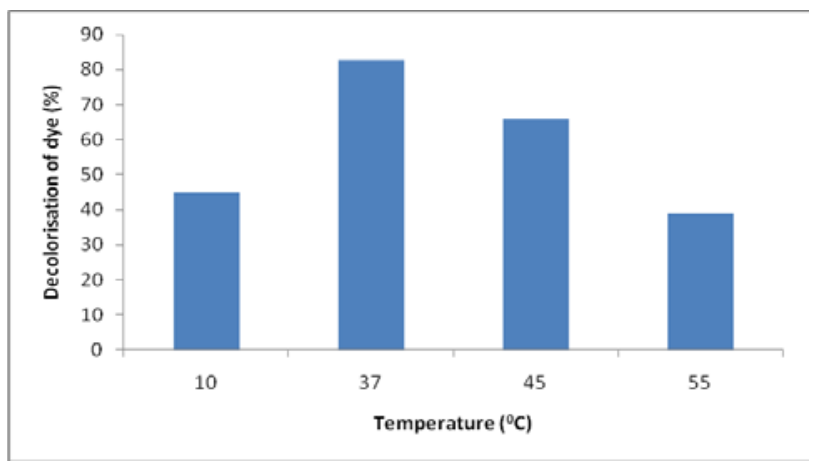

Figure 7. Effect of temperature on dye degradation

The optimum temperature for decolourization was found to be about $37^{\circ} \mathrm{C}$. All organisms have their own ability to grow at different temperature and decolourize the dye. It has been reported that Klebsiella pneumoniae RS-1 and Alcaligens liquefaciens S-1 do no decolourize Methyl Red at $45^{\circ} \mathrm{C}$ [37].

\subsection{Effect of pH on Dye Degradation}

The results of the effect of $\mathrm{pH}$ on dye degradation are given in Figure 8. The maximum dye degradation was shown at $\mathrm{pH} 7$. Dye degradation at $\mathrm{pH} 6$ \& 8 was almost similar while the minimum was found at $\mathrm{pH} 10$.

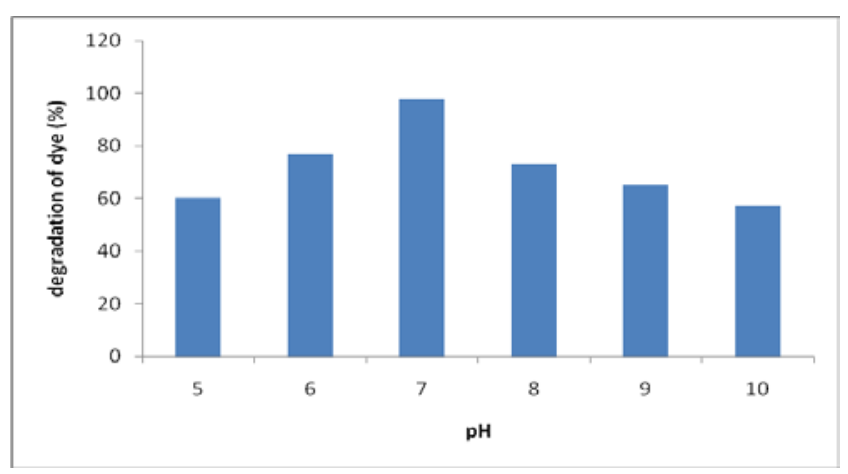

Figure 8. Effect of temperature on dye degradation

During collection, temperatures of the samples were found to vary from $32-40^{\circ} \mathrm{C}, \mathrm{pH}$ of the samples were recorded to range from 6.5-9.2. Increased $\mathrm{pH}$ is due to excessive use of carbonate, bicarbonate, $\mathrm{H}_{2} \mathrm{O}_{2}$ and $\mathrm{NaOH}$ during bleaching process [38].

\section{Conclusion}

The selected isolate which was identified as Bacillus megaterium showed maximum decolourization of turquoise blue dye within 48 hours at $\mathrm{pH}$ 7.00. The isolated culture can decolourize turquoise blue dye concentration up to $5 \mathrm{mg}$ in natural condition. The isolated strain is even able to degrade wide range of dyes. Further, $B$. megaterium species can be applied and tested at large scale degradation of this dye.

\section{Acknowledgements}

I am grateful to Charutar Vidya Mandal (CVM). Vallabh Vidyanagar, Gujarat, for providing the resources and requirements readily for the completion of this work. Bhoomi Joshi, Khyati Kabariya and Sweta Nakrani thanks to Government Science College K. K. Shastri Educational Campus Khokhara Road, Maninagar (E), Ahmedabad. Authors also would like to acknowledge Dr. Chirag Shah, Government Science College, Ahmedabad for his help and suggestion.

\section{References}

[1] Raffi, F., Hall, J.D.\& Cernigila, C.E.. Mutagenicity of azo dyes used in foods, drugs and cosmetics before and after reduction by Clostridium species from the human intestinal tract. Food and chemical Toxicology.,1997, 35, 897-901.

[2] Tyagi OD, Yadav M., A textbook of synthetic dy. AnmolvPublications PVT Ltd., 2001.

[3] Zollinger, H., Syntheses, Properties and Applications of Organic Dyes and Pigments. In: Colour Chemistry (2nd Ed). VCH Publishers, 1991, Weinheim; P. 496.

[4] Abadulla, E., Tzonov, T., Costa, S., Robra, K.H., Cavaco, P.A., et al.,Decolourization and detoxification of textile dyes with a laccase from Trametes hirsute. Appl. Environ. Microbiol., 2000, 66(8):3357-3362.

[5] Banat, I.M., Nigam, P., Singh, D., Marchant, R., Bioresour. Technol., 1996, 58, 217-227.

[6] Moawad H, El-Rahim W, Khalafallah M. Evaluation of biotoxicity of textile dyes using two bioassays. J Basic Microbiol. 2003, 43(3): 218-229. 
[7] Poots, V. J., McKy, G, \& Heakt, J. The removal of acid dye from effluent using natural absorbents -II. Water Res., 1976, 10, 10671070.

[8] McKay, G. waste colour removal from textile effluents. Am Dyestuff. Reporter, 1979, 68, 29-36.

[9] Rodríguez, A., García, J., Ovejero, G. and María Mestanza., Adsorption of anionic and cationic dyes on activated carbon from aqueous solutions:Equilibrium and kinetics. Journal of Hazardous Materials, 2009, 172, 1311.

[10] Lambrecht, R., Barros, M.A., Cossich, S.D., Silva, E.S., Matta, E.A. and Stachiw, R., Adsorption of Reactive Blue 5G dye by activatedlcarbon and pyrolyzed shale oil residue. Adsorption Science \& Technology., 2007, 25, 741.

[11] Tastan, B.E., Ertugrul, S.G., Dõnmez, G., Bioresour. Technol., 2010, 101, 870-876.

[12] Aksu Z, Kilic NK, Ertugrul S, Donmez G Inhibitory effects of chromium (VI) and Remazol Black B on chromium (VI) and dyestuff removals by Trametes versicolour. Enz. Microb. Technol., 2007, 40: 1167-1174.

[13] Ghodake GS, Telke AA, Jadhav JP, Govindwar SP. (2009) Potential of Brassica juncea in order to treat textile effluent contaminated sites. Int. J. Phytorem. 11: 297-312.

[14] City of Kingston CotCoK, By-law to control waste discharges to municipal sewers, 2000, (by-law (2000-263).

[15] City of Toronto CotCoT. Chapter 681 sewers: sewage and land drainage (municipal by-law article 1). 2000.

[16] Anastasios, S., M. Konstantinos, N. Ulrich, F. Konstantinos and V. Anastasios. Evaluation of a novel electrochemical pilot plant process for azo dyes removal from textile waste water. J. Chem. Eng., 2005, 111: 63-70.Dyes.

[17] Theodora, V., I. Poulios, M. Charalabaki, N. Kalogerakis, P. Samaras and D. Mantzavinos, 2006. Photocatalytic and sonolytic oxidation of acid orange 7 in aqueous solution. Appl. Catalysis B: Environ, 62: 159-168tuff.

[18] Pak, D. and W. Chang,. Decolourizing dye wastewater with low temperature catatylic oxidation. Water Sci. Technol., 1999, 40: 115-121.

[19] Kabita, D., S. Mukhopadhyay, S. Bhattacharjee and B. Chaudhuri Photocatalytic and sonolytic oxidation of acid orange 7 in aqueous solution. Appl. Catalysis B: Environ., 2006. 62: 159-168.

[20] Gurulakshmi, M., Sudar, D.N.P. and Mani, R.Venba, Biodegradation of Leather ACID Dye by Bacillus subtilis. Advanced BioTech., 2008, 7 (5): 10.

[21] Wong, P.K. and P.Y. Yuen,. Decolourisation and biodegradation of methylred by Klebsiella pneumoniae RS-13. Water Res., 1996 30: $1736-1744$

[22] Keharia, H., H. Patel and D. Madamwar,. Decolourization Screening of Synthetic Dyes by Anaerobic Methanogenic Sludge Using a Batch Decolourization Assay. World J. Microbiol. Biotechnol., 2004, 20: 365-370.

[23] Seesuriyachan, P., S. takenaka, A. Kuntiya, S. Klayraung, S. Murakmi and K. Aoki,. Metabolism of azo dyes by Lactobacillus caesi TISTR 1500 and effects of various factors on decolourization. Water Res., 2007, 41: 985-989.

[24] Thakur, M. C., Khan, A. and Doshi, H., Isolation and Screening of Dye Degrading Micro-organisms from the Effluents of Dye and Textile Industries at Surat, American Journal of Environmental Engineering, 2012, 2(6): 152-159.

[25] Kuo-Cheng Chen a,*, Jane-Yii Wua, Chang-Cheng Huang a, YuMin Liang a,Sz-Chwun John Hwang ba Department of Chemical Engineering, National Tsing Hua University., 2002, 300.

[26] http://www.pburch.net/dyeing/dyeblog/C1845207367/ E20110930112637/index.html.

[27] Sani, R. \& Banerjee, U. Decolourization of triphenylmethane dyes and textile and dye stuff effluent by Kurthia sp. Enzyme and Microbial Technology., 1999, 24, 433-437.

[28] Paszcezynski, A., Pasti-Grigsby, M., Goszceynski, S., Crawford R. \& Crawford, D.L. Mineralization of sulfonated azo dyes and sulfanilic acid by Phanerochaete chrysosporium and Streptomyces chromofuscus. Appl.Environ. Microbiol., 1992, 58, 3598-3604.

[29] Yatome, C., Matsufuru, H., Taguchi, T and Ogawa, T., Degradation of 4 dimethylaminobenzene-2-carboxylic acids by Pseudomonas stutzeri. Appl. Microbiol. Biotechnol., 1993, 39: 778-781.

[30] Dykes, G.A., Timm, R.G. and VonHoly, A.,. Azoreductase activity inbacteria associated with the greening of instant chocolate puddings. Appl. Environ. Microbiol., 1994, 60:30273029.

[31] Coughlin, M.F., Kinkle, B.K., Tepper, A. and Bishop, P.L. Characterization of aerobic azo dye degrading bacteria and there activity on biofilms. Water Sci. Technol., 1997, 36:215-220.

[32] Oranusi, N.A.and Mbah, A.N.. Utilization of Azo and Triphenylmethane dyes as a sole source of carbon, energy and nitrogen by Bacillus sp. African J.Appl. Zool. Environ. Biol., 2005, 7: 87-94.

[33] Oren, Aharon, Gurevich, Peter, Azachi, Malkit, Henis, Yigal, Microbial degradation of pollutants at high salt concentrations. Biodegradation, 1992, 3:387-398.

[34] Ventosa, A and Aharon,. Biology of moderately halophilic aerobic bacteria. Microbiol. Mol. Biol. Rev., 1998, 62(2):504-544.

[35] Ganesh, R. Fate of Azo Dyes in Sludges, Master's Thesis. Polytechnic Institute and State University, 1992, Virginia. P. 193.

[36] Prayeen,G and Bhatt,S,Decolourization of Azo dye Red 3BN by bacteria, Department of Biotechnology, Aryan Institute of Technology.,2012, Vol. 1(5), 46-52.

[37] Wong, P.K. and Yuen, P.Y. Decolourization and biodegradation of N,N-dimethyl-p-phenylenediamine by Klebsiella pneumonia RS-13 and Acetobacter liquefaciens S-1. J. App Microbio., 1998, 85, 79-87.

[38] K.R. Mahbub, A. Mohammad, M.M. Ahmed and Salma Begum, Decolourization of Synthetic Dyes Using Bacteria Isolated from Textile Industry Effluent. Asian Journal of Biotechnology, 2012, 4 129-136. 